\title{
Illusions and Knowing What Is Real
}

\author{
John M. Kennedy, Christopher D. Green, Andrea \\ Nicholls, and Chang Hong Liu \\ University of Toronto
}

\begin{abstract}
Geometrical illusions are displays that give false impressions that observers take to be accurate. They have traditionally been cited as evidence against the naive realist claim that people see the world as it "really" is. Such illusions, however, often depend on their being viewed from a single vantage point (Kennedy \& Portal, 1990). In Gibsonian terms, they depend on the availability of impoverished information. In this study, spatial transformations were applied to line-length (Sander parallelogram) and area (Jastrow curves) illusions to provide information to observers about veridical size. In particular, the reversal of certain parts of the displays resulted in informative invariants that specified the veridical nature of the parts. Most observers were able to use the information.
\end{abstract}

In this article we consider the status of geometrical illusions and possible informative perceptual transformations vis-à-vis problems of knowledge. We show how information for veridical size arises via the movement of parts of illusions, even though the illusory impressions are not dispelled.

Geometrical illusions are usually flat displays of lines or black-and-white regions in which observers perceive length, shape, or area incorrectly. Popular examples such as the Müller-Lyer, Ponzo, and Poggendorf illusions have figured prominently in the philosophical discussion of the nature of knowledge for more than 100 years. These illusions are said to present problems for the naive realist, who argues that people perceive exactly and only what is there in the world. They are also said to provide support for the skeptic, who counters that there are many instances in which people know that their senses deceive them and that they therefore have no way of knowing when or if they can trust their senses. This critique has traditionally been called the argument from illusion.

Requests for reprints should be sent to John M. Kennedy, Department of Psychology, Life Sciences Division, University of Toronto/Scarborough College, 1265 Military Trail, Scarborough, Ontario MIC 1A4, Canada. 
The argument from illusion can lead one to a number of different epistemological positions. The most extreme is full-blown skepticism, the belief that nothing can be known and that people are well advised to stop the very attempt to understand the world. Alternatively, one could argue for a causal theory, as have many empiricists. Causal theories state that things in the world cause certain perceptual entities to come into being. For Locke, they cause "ideas" to come into being. Locke argued that it is these ideas and only these ideas that people actually perceive. Locke $(1689 / 1959)$ divided the world of perceptual qualities into two kinds that he called primary and secondary. Primary qualities are those that Locke $(1689 / 1959)$ believed to be "utterly inseparable" (Vol. 1, p. 169) from the objects themselves. Included in this group were solidity, extension, figure, and mobility. Secondary qualities are those that are "nothing in the objects themselves but powers to produce various sensations in us" (Locke, 1689/1959, Vol. 1, p. 170). Locke took color to be the single best example of a secondary quality.

Berkeley (1710/1963), on the other hand, opted for idealism, the belief that there are no things in the world independent of people's perception of them: "The object and sensation are the same thing, and cannot therefore be abstracted from each other" (p. 32). In some respects more radical than Berkeley, Hume (1740/1978) was especially skeptical of the warrant for claiming that external objects are the cause of perception: "That our senses offer not their impressions as the images of something distinct, or independent, and external, is evident; because they convey to us nothing but a single perception, and never give us any thing beyond" (p. 189). Hume noted that illusions indicate that people perceive impressions, albeit ones caused by external objects.

Kant tried to weaken the extreme skeptical position by arguing that there was indeed a "real" world-the noumena-apart from perception of it. He contended, however, that one could not have any direct knowledge of the noumena. Human knowledge was of the phenomenal world only, the world as perceived. Kant also argued for the indispensable role of reason in the acquisition of knowledge. Reason and observation work together in this regard. "Thoughts without content," wrote Kant (1781/1965), "are empty, intuitions [i.e., roughly, sensations] without concepts are blind" (p. B76).

Many later empiricists objected to the assertion that people are forever separated from the world by a "veil of appearance," as it came to be known. Indeed, philosophers eventually developed an analysis of propositions about objects called phenomenalism. Although often mistaken for a philosophy of perception itself, phenomenalism was intended as a bridging argument that allowed one to avoid, on the one hand, the ontological commitments of materialism and, on the other hand, the danger of slipping into idealism and, ultimately, solipsism. In essence, the phenomenalist position claims that all talk about objects in the world can, in principle, be reduced to talk about sense data, thus avoiding all metaphysical speculation about what is real. 
John Stuart Mill (1865/1979), who was one of the leading phenomenalists (but not the most radical) defined matter as nothing more than the "permanent possibility of sensation" (p. 183; also cited in James Mill, 1869/1967, p. 448). Other phenomenalists, such as Ernst Mach, were far more radical in their positions, arguing that science itself is nothing more than the discovery of the statistical relations that hold between given sets of sensations. Later phenomenalists, such as Ayer (1940), have argued that the disagreement between idealists and causal theorists is not at all about the "facts" of perception but about what language is to be used in describing perception. True to his logical positivist allegiance, Ayer believed that because there can be no empirical evidence brought to bear on whether something exists that causes a given perception (because people have only perception itself to go on), the entire argument is vacuous-"unempirical nonsense," to use the logical positivists' favorite term of derision.

The primary difficulty with all of these positions is that they each invoke a separate set of perceptual entities that are, explicitly or implicitly, said to be the objects of perception. Such entities are useful in explaining how, to use a classic example, Shakespeare's Macbeth could see a dagger when no dagger was present: He had the sensation of a dagger in the absence of an actual dagger. These positions founder on their inability to distinguish Macbeth's predicament from a time when there actually (i.e., extensionally) was a dagger before him. They are further discredited because they give no account of how two people might be said to see the same thing. This has profound implications for epistemology and science itself, for if all anyone ever sees is one's own sense data, then there is no sense in which observations can be verified by others, no way that consensus can really be achieved. In addition, they seem to introduce an infinite regress of nested homunculi.

In the face of the difficulties of phenomenalism, sophisticated versions of realism have been offered that account for the problems posed by illusions without invoking such problematic intermediate entities. The best known of these was the new realism of the early 20th century, initiated by British educational theorist T. P. Nunn (1909) and brought to its height by Harvard philosophers E. B. Holt and R. B. Perry (Holt et al., 1912). The new realist position begins, as does that of naive realism, by arguing that both primary and secondary qualities are intrinsic to the external objects of perception, which are perceived just as they are. In order to come to terms with the argument from illusion, however, the new realists made the remarkable claim that all of the features of the percept of an object are actually features of the object itself: Objects seen under colored light just are so colored; sticks apparently bent by being half immersed in water just are so bent; buildings foreshortened when being seen from a certain perspective just are so foreshortened. In each example, the apparent divergence from reality is considered to be one of the object's real aspects. Following Meinong (1904/1960), however, the new realists claimed that only some of the object's multiple aspects are perceived at any given time. 
To make sense of the new realist position, it is necessary to distinguish between what Holt called the "physical object" from what is usually called the material object. Materialism was no part of the new realist position. "The picture I wish to leave," wrote Holt et al. (1912), "is of a general universe of being in which all things physical, mental, and logical, propositions and terms, existent and non-existent, false and true, good and evil, real and unreal subsist" (p. 372). Subsistence is a term that was coined by Meinong to denote the things, such as numbers and relations between things, that are, in some sense, real (more so than, say, unicorns or round squares) but that do not exist materially, such as tables. Holt et al. had extended this limited category to all of the things of the universe. "The entities of the universe," he continued, "have no substance, but if the spirit is weak to understand this, then let the flesh, for a season, here predicate a neutral substance" (Holt et al., 1912, p. 372). Thus, the new realists abandoned materialism for this "neutral substance" in order to embrace an epistemological realism.

Although it created quite a stir, some of the bizarre implications of the new realism (e.g., the real and the unreal subsisting equally, objects changing their color under different-colored light, buildings changing their shape as a person moves around them, etc.) ran so contrary to common sense that it was destined to burn short, even if brightly. By 1920, the movement was over, but its impact stimulated a fresh examination of perceptual realism, a new approach that would not be subject to the pitfalls of the Holt et al. (1912) approach.

One of the most influential articulations of the new sophisticated realism was provided by one of Holt's students, psychologist J. J. Gibson (1966, 1979/1986). In Gibson's ecological psychology, realism is defensible if the observer has information available in the environment adequate to specify the object. Gibson called the use of such information "direct perception." There has been much controversy concerning the exact meaning of the term direct in the context of ecological psychology. Perception, all agree, is "causally" mediated. Since Helmholtz, however, some theories have contained an inferential step, mediating psychologically between sensory effects (in the perceiver) and the normal fully developed percept (in the perceiver). Inference theories have advocated "indirect" perception in the sense that one actually perceives some intervening perceptual entity (e.g., sense data) that is used to infer the existence of the object that caused it. "Direct" perception in the ecological psychology sense is a different matter. Ecological realists do not, of course, advocate causally unmediated contact with the world but that information about the objects of the world is continuously available to the perceiver and it is this that people "pick up." Also, for ecological realists, perception is direct in the sense that the inferential step is not needed. Perception is causally mediated but epistemically unmediated. In ecological psychology, the term indirect is used in the case in which a physical entity intervenes between the thing and perception, such as a picture. Ecological information is often obtained as a result of movement in the 
environment, most notably the perceiver's movement through the environment. Such movement is accompanied by variants and invariants in the optic array across time, which indicate what is changing and not changing in the environment. It is important to note that the information is independent of any inferences made by the perceiver. The information is (a) a fact about the environment with respect to a vantage point, (b) a fact of the optic array in an environment, and (c) a feature that allows a direct perceptual pick up of environmental properties by the visual system.

Although his position changed over the years, Gibson (1966) posited that the analysis of illusion is relatively unimportant because geometrical illusions are artificial, typically rely on an impoverished array of information, or both. In ecological optics, the examination of a scene from a single vantage point is, at times, insufficient (hence, the problem of pictures that are restricted to a single vantage point). The question of the perceptual result of a poverty of perspectival information is the focal point of what follows. Normal perception of an objectby an observer in an environment-can have many perspectives, and it is by detecting relations between these multiple perspectives that the information is said to be obtained. An important implication of this critique of the argument from illusion is that if several different views of a given illusion figure were made available, the perceiver could determine the truth about the figure. But which views? And will the observer use the information?

In this regard, Gehringer and Engel (1986) had people observe an Ames room from the vantage point that gave the impression of rectangularity but then had them walk across the front of the room, presumably allowing them to pick up information about its true shape. Afterward, on viewing the room from the initial vantage point again, the participants' perceptual impressions of the room's shape were not completely veridical, in apparent contradiction of the Gibsonian prediction. The impact of the illusion decreased from $100 \%$ to $8 \%$, but Gehringer and Engel claimed that if Gibson were right, the illusion should be completely dispelled. This seems an unnecessarily stringent criterion, however, because there is no guarantee that the information the participants obtained by walking only across the front of the room was that which is necessary to correctly judge veridicality. A true test of ecological theory would have allowed the participants to explore the room without restriction (see Schiff, 1988). Furthermore, Gehringer and Engel asked the participants their perceptual impression after touring the room rather than what they thought to be true, thus seemingly restricting the answer, at least for some participants, to what was perceived from a single vantage point. This is a clear violation of the Gibsonian spirit.

Alternatively, it could be that some participants simply did not make appropriate use of the information made available by walking across the front of the room. Gehringer and Engel (1986) seemed to assume that the simple presence of information would guarantee the apprehension of its significance. 
Clearly, however, this cannot be so. Although perception may rely on information, perception must also be "educated" as to how to use such information before it makes optimal use of it. This is not a simple ad hoc to shore up ecological realist theory but derives directly from the Gibsonian corpus itself (Gibson, 1966, pp. 51-52). Moreover, in spite of the flaws in Gehringer and Engel's conception and procedure, the size of the decrease in the magnitude of the illusion was impressive and to regard the results as a refutation of the realist position seems unwarranted. Runeson (1988) pointed out other unwarranted steps in the Gehringer and Engel analysis of the relation between their stimulus conditions and ecological conditions under which information can be said to exist. Also, Runeson disputed their claim that there was a remainder to the illusion effect after the participants moved. Here, we consider the perceptual impressions the participants reported and what Runeson called the perceptual utilization of information under various conditions and described as an important area for empirical research.

Research by Kennedy (1987) distinguished the observer's "perceptual impressions" from what the observer "knows" about what is observed. Kennedy used the term perceptual impressions for what Gibson called "the looks of" a scene (Natsoulas, 1991). Kennedy had observers view a standard illusion display (Poggendorf) from three different perspectives. When observers "sighted down" the Poggendorf's diagonal, the illusion was dispelled; the impression corresponded to veridical fact (cf. Parks \& Hui, 1989). Nevertheless, Kennedy's observers were unable to tell at better-than-chance level which impression revealed the "true" state of affairs. Evidently, it is not enough to simply have more than one view, even if that view dispels the illusion. Some additional properties or relations between views is necessary as well. This is an important point for realist theory. Information does not consist of impressions or looks of objects. It arises from specificity of an optic array to its source. "Sensory" impressions, on the other hand, are "occasional and incidental symptoms of perception," but they are not entailed in perception (Gibson, 1967, p. 48).

Kennedy and Portal (1990) developed this experimental paradigm further. In one experiment they had observers view two geometrical illusion displays (Hering and Titchener) from three perspectives each. From at least one of the perspectives, the illusion was present and from at least one other the illusion was dispelled. The observers were then asked which impression was veridical. As in Kennedy (1987), they were unable to select the correct one at better than chance. In a follow-up experiment, observers were shown yet another illusion display (Orbison) from four perspectives set $360^{\circ}$ around the display. In this case, however, none of the perspectives gave rise to a veridical impression. Nevertheless, after this procedure, 19 of the 22 observers were able to determine the true state of affairs. Kennedy and Portal argued that this intriguing finding was attributable to the observers obtaining the information necessary to determine veridicality in the final experiment, despite the absence of any veridical 
impression. Kennedy and Portal argued that when the illusory display was rotated, the set of perspectives yielded not only incorrect impressions but also invariants that specified the relevant shape properties of the figure. By contrast, observers in the Poggendorf, Hering, and Titchener experiments, although they received a veridical impression, were said to have not obtained the information necessary to know what was veridical.

Although intriguing, the Kennedy and Portal (1990) study investigated only the perceived symmetry of illusion displays. Characteristically, though, geometrical illusions involve matters such as size (e.g., area and length in the Jastrow curves and the Sander parallelogram). One purpose of this research was to extend the findings of Kennedy and Portal to size perception. To this end, the experiments reported here used the Jastrow and Sander illusions in order to investigate whether a certain informative transformation-reversal-would enable observers to determine the veridical nature of the displays. Reversal can, in principle, provide definitive information about area and length. In the reversal transformation, two features of a display that appear to be of different sizes are exchanged with one another relative to the rest of the illusion display. If the apparent differences in size are real, then the reversal should not substantially change its relative appearance (i.e., the initially smaller feature should still appear smaller and mutatis mutandis for the larger feature). If, on the other hand, the two features should reverse their apparent relative sizes after the transformation (i.e., the initially smaller feature now appears larger), then this is information that the two features are the same size.

\section{METHOD}

Two experiments were carried out. In each study, a group of observers was shown a set of transformations of one geometrical illusion display. After each transformation the observers were asked questions concerning their perceptual impressions and what they believed the true set of affairs to be.

\section{Participants}

The participants were 67 undergraduate students: 34 in the Jastrow experiment and 33 in the Sander procedure. They were drawn from undergraduate perception-and-cognition courses offered at the University of Toronto. The participants' ages ranged from 19 to 44 . All but 10 were between 19 and 24 years old, and only 5 were over 30 . They all had normal or corrected-to-normal vision.

\section{Stimuli}

The materials used were flat black-and-white line drawings of the two geometrical illusion figures. Each of the Jastrow curves was $6.5 \mathrm{~cm}$ long. The Sander 
parallelogram had sides of $8.5 \mathrm{~cm}$ and $4.0 \mathrm{~cm}$ in length. The interior $V$-shape of the Sander illusion figures was drawn on a transparency so that it could be reversed with respect to the parallelogram. The length of each leg of the "equal" $V$-shape was $5.7 \mathrm{~cm}$. The lengths of the legs of the "unequal" V-shape were 5.0 $\mathrm{cm}$ and $6.3 \mathrm{~cm}$ (see Figures 1 and 2 for examples of the figures used). Note the three marks on the base lines. These were added to aid in observing the results of transformations.

\section{Procedure}

Seated observers viewed the displays, which were laid horizontal on a table under standard interior illumination, through an aperture that was $8.0 \mathrm{~cm} \times$ $10.5 \mathrm{~cm}$. The lower border of the aperture was $22 \mathrm{~cm}$ above the table top. The distance from the aperture to the center of the display was $30 \mathrm{~cm}$.

In Experiment 1, observers were first shown the Jastrow curves side by side and then were shown the two Jastrow curves one above the other (left edges separated by $1.3 \mathrm{~cm}$ ). (We had repeated the experiment without showing the curves side-by-side initially. The results were the same. Here we report the fuller version of the procedure.) In both conditions, the observers were asked which one looked larger. They were then asked which one they thought was really
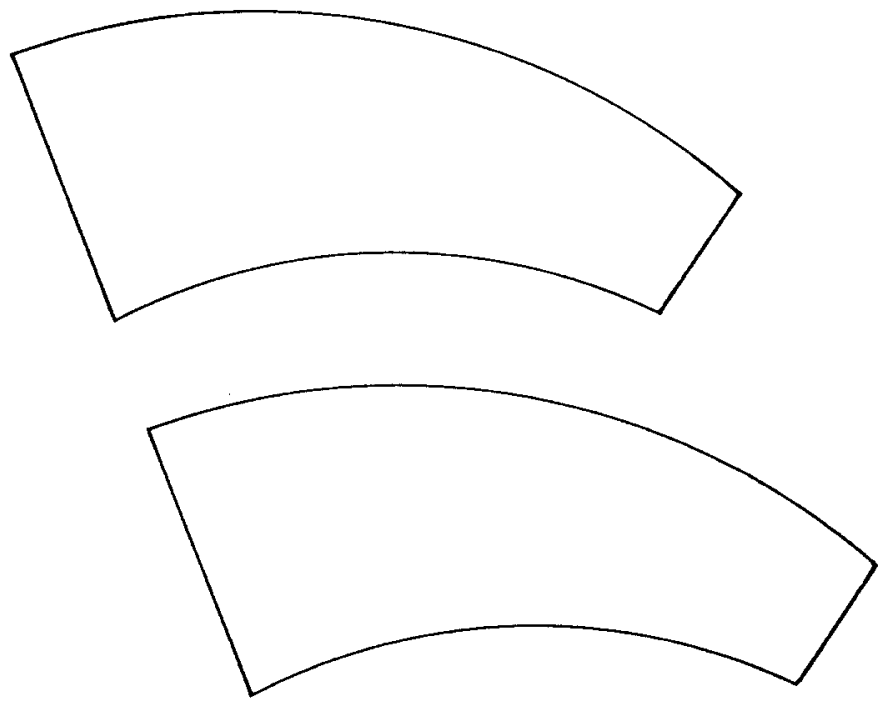

FIGURE 1 Jastrow illusion. The two curves, which are equal, appear unequal when placed one above the other. They appear equal when placed side by side. If the upper figure is moved so as to become the lower figure, it will look larger than its companion. This reversal offers information that the two figures are really equal, even if they were never to appear equal. 

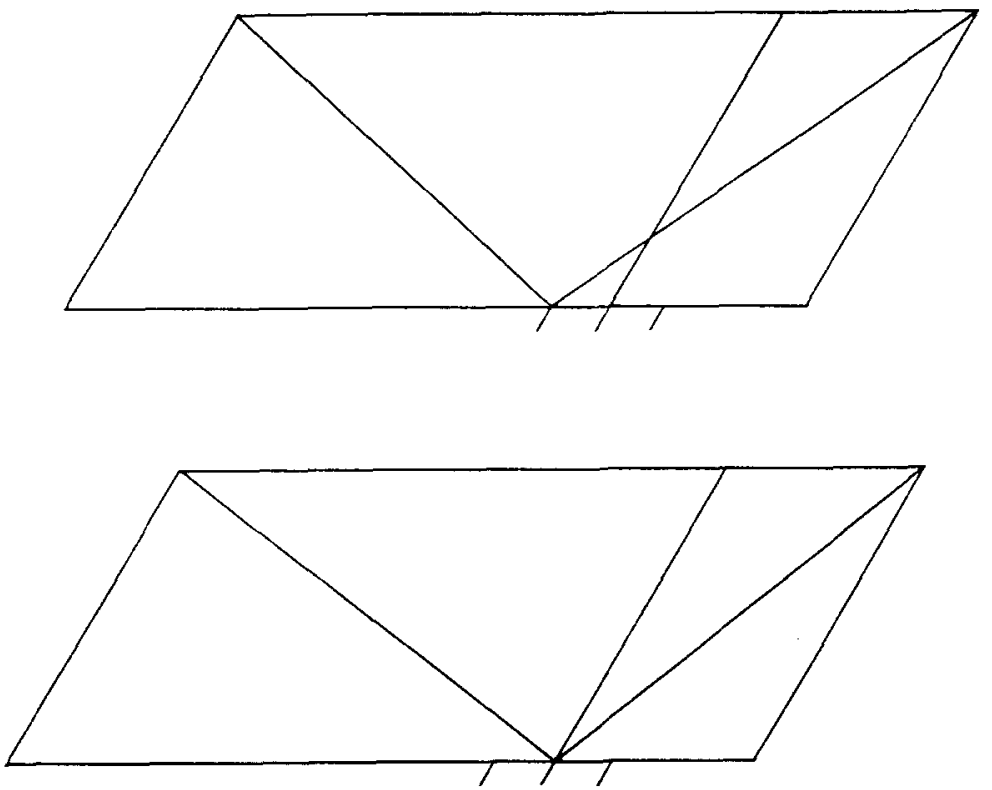

FIGURE 2 Sander parallelogram illusion. The V-shapes in the interior of the parallelogram appear unequal when they are truly equal. Rotating the $V$ with equal-length limbs $180^{\circ}$ within the parallelogram leaves the display entirely unchanged. This provides information that the limbs of the $\mathrm{V}$ are physically equal. The $\mathrm{V}$-shaped limbs can be unequal and positioned to take advantage of the illusion so that they appear equal. Rotating this $\mathrm{V} 180^{\circ}$ produces a change in its appearance. The limbs of the $\mathrm{V}$ become unequal looking. The locus of the tip of the $V$ moves substantially along the base of the parallelogram (from the leftmost of the three marks on the base to the rightmost). The change constitutes information that the limbs must be unequal in size.

larger. If asked what was meant by "really," the experimenter replied, "if it were to be measured." Before the transformation from side by side to one above the other, the figure being moved was partially covered with a piece of opaque paper so that comparisons could not be made by the observer during the transformation, when the two displays became coincident. While moving the figures the experimenter explained, "All I am doing is sliding one over the other." The opaque paper was then removed from the figure that was moved and the observer was asked the same two questions again: "Which one of the figures looks larger?" and "Which do you think is really larger?" The upper figure was then covered and moved so that it became the lower figure. The questions were posed a final time. The observers were then asked if they had ever encountered the Jastrow figure before. The optional answers offered were never before, a few times (i.e., 1-4), or several times, (i.e., 5 or more).

The Sander figures were used in Experiment 2. The display format was similar 
to that for the Jastrow figures. The Sander figures were viewed through the same aperture, lying at the same location.

The V-shapes of the Sander figures were on transparencies. Initially, the unequal-length-limbs $\mathrm{V}$-shape was presented so that, in the context of the Sander figure, the limbs appeared equal in length. That is, the right limb of the $V$ was longer, and the parallelogram on which it was placed "leaned" to the right (meaning the short left side of the parallelogram made an acute angle with the long horizontal baseline). On its initial presentation, the equal-length $\mathrm{V}$ appeared to be longer on the left side, under the influence of the Sander figure "leaning" to the right.

The observers were shown a Sander figure and were assigned at random to equal or unequal $V$-shapes. They were asked whether the limbs of the $V$ looked equal or unequal and what they were really. The wording was as follows:

Which limb of the V-shape looks longer? Or do they look the same size? Please note I am asking you which looks longer. Now let me ask you which limb is really longer. If you were to measure the limbs which limb would be found to be really longer? Would they be found to be the same size?

The observer was asked to notice the location of the tip of the $V$ with respect to the three marks on the base of the parallelogram.

Next, the transparency with the $V$-shape was flipped $180^{\circ}$ to reverse left and right. During the flip a small opaque occluder hid the $V$ from view, as in the experiment with the Jastrow. The questions were then asked again, first the "looks" question, then the "really" question. Notice that the equal-length $\mathrm{V}$ display looked longer on the left on initial presentation, and the appearance did not change after the flip. The unequal-length display appeared to have equal limbs on first presentation and to have a longer limb on the left after the flip.

Following initial presentation and the flip of one Sander figure, the second Sander was presented. The first Sander was then repeated (arranged as on the initial presentation) and flipped again. Observers were asked the "really" question one final time about this display. Finally, the second Sander was repeated and flipped, and the "really" question was posed one last time.

For observers to be correct on the "really" question after the flip, they had to judge one $\mathrm{V}$ looking longer on the left as actually having equal limbs, and another display also looking longer on the left as actually having unequal limbs and truly being longer on the left.

\section{RESULTS}

The results are given in Tables 1 (Jastrow) and 2 (Sander). Table 1 shows that 34 observers participated. Data from 3 observers were eliminated either because 
TABLE 1

Jastrow Illusion Results

\begin{tabular}{lc}
\hline Participants at Each Step in the Procedure & $n$ \\
\hline $\begin{array}{l}\text { 1. Subjects participating } \\
\text { 2. Subjects who were unfamiliar with the illusion and there was no error in procedure }\end{array}$ & 34 \\
3. Subjects who reported the two shapes were really equal in size after viewing them \\
$\quad \begin{array}{l}\text { side by side (vs. } 3 \text { who said one shape was really larger) } \\
\text { 4. Subjects who reported the two shapes were really equal in size after viewing them } \\
\text { one above the other (vs. } 15 \text { who said one was really larger) }\end{array}$ \\
$\begin{array}{l}\text { 5. Subjects who reported that the two shapes were really equal in size after viewing } \\
\text { them again one above the other, in reversed orientation to ltem 5 (vs. } 8 \text { who } \\
\text { said one was really larger) }\end{array}$ & 28 \\
\hline
\end{tabular}

TABLE 2

Responses to Sander V-Shapes With Equal- and Unequal-Length Limbs

\begin{tabular}{|c|c|c|c|}
\hline \multirow[b]{2}{*}{ Question } & \multicolumn{3}{|c|}{ Participant Responses } \\
\hline & Equal & Left & Right \\
\hline \multicolumn{4}{|c|}{ Initial queries } \\
\hline \multicolumn{4}{|l|}{ Appearance } \\
\hline Equal & 5 & 28 & 0 \\
\hline Unequal & 15 & 6 & 12 \\
\hline \multicolumn{4}{|l|}{ Reality } \\
\hline Equal & 20 & 1 & 12 \\
\hline Unequal & 17 & 15 & $1^{a}$ \\
\hline \multicolumn{4}{|c|}{ After first $180^{\circ} \mathrm{flip}$} \\
\hline \multicolumn{4}{|c|}{ Appearance } \\
\hline Equal & 3 & 30 & 0 \\
\hline Unequal & 0 & 33 & 0 \\
\hline \multicolumn{4}{|l|}{ Reality } \\
\hline Equal & 28 & 5 & 0 \\
\hline Unequal & 8 & $25^{\mathrm{b}}$ & 0 \\
\hline \multicolumn{4}{|c|}{ Final queries } \\
\hline \multicolumn{4}{|l|}{ Reality } \\
\hline Equal & 26 & 6 & 1 \\
\hline Unequal & 10 & $23^{b}$ & 0 \\
\hline
\end{tabular}

${ }^{a}$ Right is the correct response. 'beft is the correct response.

they were familiar with the illusion $(n=2)$ or because of an error in procedure $(n=1)$. Of these observers, 28 reported that the two curves were really equal in size after viewing them side by side ( $p<.01$, binomial two-tailed), whereas 3 said they were really unequal. Because all of the observers said the shapes looked equal when they were side by side, the 3 who deemed one to be larger were likely to be second-guessing the experiment.

After viewing the shapes one above the other, all observers reported that the 
lower curve looked larger. When asked about the real sizes, only 16 then said that the two shapes were really equal, whereas 15 then deemed that one was larger (ns). After viewing the shapes one above the other but in reversed order, 23 observers said that the two shapes were equal ( $p<.01$, binomial two-tailed).

In the Sander experiment, 33 observers were tested. In the final question about the real length of the limbs, 33 observers were tested. Responding to the initial question about the appearance of the displays, 28 observers said that the left limb of the equal-length display looked longer, and 5 said that the limbs looked equal (i.e., the illusion was effective). In addition, 15 observers said that unequal limbs looked equal, 6 observers said that the left limb looked longer, and 12 observers said that the truly longer right limb looked longer. Evidently, the figure generally offered the illusion that the two limbs were equal in length.

When the observers were asked what was really correct about the equallength $\mathrm{Vs}, 20$ observers judged that they were really equal, 1 observer said that the left limb was longer, and 12 observers said that the right limb was longer. Regarding the unequal-length limbs, 17 observers said that they were equal, 15 observers said that the left limb was longer, and 1 observer said that the right limb was longer. The correct answer was the right limb. Evidently, the observers were misled.

When the displays were flipped over, 30 observers described the equal-length $\mathrm{V}$-shape as looking longer on the left, and 3 observers described the limbs as looking equal. The unequal-length $\mathrm{V}$-shape was described as looking longer on its longer side (left) by all of the observers (now that the illusion boosted the perception of a true length difference). When asked what was really correct, 28 observers described the equal-length figure as being truly equal, and 5 observers said that the left limb was longer. Also, 25 observers correctly picked out the longer limb (left) of the unequal-limb $\mathrm{V}$, whereas 8 observers deemed the limbs to be equal.

To the final question about what was really correct, following a repeat of the initial appearance and the flip of the Vs, 26 observers judged the equal-length limbs to be equal, whereas 6 observers said that the left was longer and 1 said that the right, $\chi^{2}(2, N=33)=31.8, p<.001$. Also, 23 observers selected the truly longer limb (the left), 10 observers still deemed the limbs to be equal, and no one selected the right limb as being longer, $\chi^{2}(2, N=33) 24.2, p<.001$.

\section{DISCUSSION}

Transformations lead observers to discern what is correct about the displays despite illusion. The transformations did not dispel the illusory impressions, but observers gained information nonetheless.

Viewing the Jastrow figures side by side gave most observers the correct impression of the relative size of the figures. Viewing one figure above the other 
instated the illusory impression and evidently led many to accept the impression as a guide to what was true. However, after the Jastrow figures reversed their locations, and the size difference remained in favor of the lower figure, the majority appreciated that the figures were equal in size. Evidently, having a correct impression first did not ensure that the observers would not be misled by the onset of an illusory impression. More important, however, the presence of a continuing illusory impression did not prevent most observers from realizing the significance of the results of the transformation.

Viewing the Sander figures reversing led most observers to distinguish the equal-length $\mathrm{V}$ and the unequal-length $\mathrm{V}$. Notice that the observers were not told that one figure was different from the other. They were free to call both $\mathrm{Vs}$ equal or unequal. One transformation (or flip) seemed to be sufficient for most observers to discern what was correct. Prior to the flip, there seemed to have been a considerable amount of guessing. For both the equal and unequal Vs, responses were fairly evenly divided between the erroneous categories, when observers were asked what was really the case, prior to the flip. The observers seemed to realize that there was an illusion because they did not follow their impressions when asked what was really true, but they distributed their guesses fairly evenly across erroneous options.

Most observers were guided appropriately by the information given by the left-for-right transformation of the $V$. However, 5 observers failed to pick the correct alternative for the equal-length $\mathrm{V}$ after the flip, and 7 observers were incorrect when the procedure was repeated prior to the final query. Eight observers were incorrect after the flip when asked about the unequal-length limbs, and 10 observers made errors when the procedure was repeated. Revealingly, only 1 observer was totally incorrect on the final query, calling the equal display unequal and the unequal display equal. Therefore, most observers who made errors were not purely second-guessing (i.e., reversing the implications of any information they were obtaining). The most common combination of error and correct judgment on the final query was calling both stimuli equal ( 9 observers). This was interesting because both stimuli looked as though the left limb was longer. The observers generally rejected the final appearance of the displays. However, some did not differentiate between the stimuli, probably because they failed to notice the differences between the transformations or to realize the significance of the differences. Furthermore, no observer called the equal display unequal and called the short (right side) limb of the unequal display the long one. This would be the exact converse of the information made available by the flip-second-guessing indeed.

In their experiment on the Ames distorted room illusion, Gehringer and Engel (1986) found strong effects of informative transformations and a small residual illusion $(8 \%)$. We found that most observers used the available information, but not all did. We distinguished "looks" and "really" questions. Gehringer and Engel did not. Veridical impressions of the Jastrow were afforded 
at the outset of the procedure, and a veridical impression that the Sander unequal-length $V$ had a longer left limb was offered during the final queries. Gehringer and Engel's procedures might not have ensured that most observers had a veridical impression while responding to the questions. It may be that their procedure never gave any observer a veridical impression but afforded appropriate information about the proportions of the room. The residual effect they found could have been caused by some observers failing to use the information, failing to gain veridical impressions, or both. Recall, in this connection, Gibson's (1966) point about "options" in perceptual experience: that an experimenter must be careful to distinguish at times when instructing the observer about what to report:

It is as if the same stimulating event had two possible poles of experience, one objective and the other subjective. There are many possible meanings of the term sensation, but this is one: the detection of the impression made on a perceiver while he is primarily engaged in detecting the world. (Gibson, 1966, p. 99)

We suggest that Gehringer and Engel's participants might have been well aware of the true shape of the Ames room but thought that the experimenters wanted them to report some perceptual impressions that were not consistent with this awareness. Our own observations of distorted rooms suggest that the impression is modified incompletely at times, albeit in a veridical direction. It is possible to be perfectly aware, as a result of viewing the display from several angles, that the proportions of the distorted room are much more awry than one's incompletely corrected impressions (from the standard vantage point on the room). Also, we have found that the incompletely corrected impressions can be variable. Attention to minor textural detail such as paint marks or dust on the rear wall of the distorted room can play a role in varying the impressions. Seeking these details to help correct one's impressions can be motivated by the awareness that the room is awry. It follows that perceptual information and the awareness it allows (of environmental properties and the perceiver's relationship to those properties) must be separated from the accompanying impressions and the awareness they allow. One can look at a tilted square with a painter's attitude and notice "convergence." That is, this "pictorial attitude" allows one to be aware that a frontal-parallel picture surface, depicting the tilted square, would contain converging lines to show the parallel sides of the square. The pictorial attitude enables the viewer to have an impression of convergence while, at the same time, the awareness that the object in the environment has parallel sides. Our experiments showed that perceivers can have impressions of size differences from illusions that they are aware are not present in the actual objects. We note that observers can undo the pictorial attitude and regain the impression of parallels in the environmental object. The same cannot be said for our observers faced with geometrical illusions because the illusory impressions were still plainly 
evident after the informative transformations. The independence of the impressions from the informative transformations is a key lesson of the argument from illusion as far as ecological psychology is concerned.

In ecological theory, invariants and variants in transformations constitute information for unchanging and changing properties of the world. Consider how this formula applies to the Sander and Jastrow illusions with parts undergoing $180^{\circ}$ flips. The Sander $V$ with equal-length limbs does not change its appearance after the flip, but what is it about the display that is visibly invariant, giving useful information about size relations? On the parallelogram's left side, one limb of the $\mathrm{V}$ stretches from the top vertex to a fixed mark on the base. This is true before and after the flip because the appearance remains constant. Hence, the old left limb before the flip is equal in length to the new left limb after the flip. The $V$ must have equal-length limbs. The Sander $V$ with unequal-length limbs behaves differently. Its left limb prior to the flip stretches from the top left vertex to the nearest of three fixed marks on the base. After the flip, the left limb no longer stretches to that fixed mark. Consequently, the two limbs of the $\mathrm{V}$ are unequal. The new left limb after the flip stretches to the farthest of the three fixed marks. Hence, it must be longer than the old left limb prior to the flip.

In the Jastrow illusion, the apparent size difference is exactly the same in favor of the lower shape before and after the shapes exchange positions. If the two shapes were different in size, when the apparently smaller one replaced the apparently larger one, it should have filled less space. It does not. The two figures reverse their locations, and the size difference is constant in direction. The size difference is invariant with placement and is not invariant with the identity of the shapes, one might say. The Sander has marks on the base to facilitate observing variants and invariants, but logically the Jastrow's analysis runs on the same basis as the Sander's equal-length $V$ limbs. They appear longer on the left before and after the flip, despite the limbs exchanging positions. In both cases, the relations evident before and after the flip constitute information not present in any single observation. In keeping with Gibson's (1979/1986) point that some artificial displays such as toys, pictures, and words may make it much easier to extract and abstract the invariants that specify the environment, we contend that geometrical illusions may make it vastly more difficult to appreciate what invariants to search for but that the invariants may be there nonetheless.

The information available in a flip transformation allows the correct sizes of the exchanged parts of a figure to be ascertained directly. The information is present in a set of effects. It is not coded, depicted, or represented in some other medium before it becomes information. It is a relationship in a flip that is specific to the facts of the sizes of the parts. Information present as a result of an event is no more direct or indirect than information present in a frozen moment. Information is defined by specification. It does not matter how the specification is arranged, statically or kinetically. 
It should be noted that we have not explained the illusions here. We recognize that the chief goal of a century of psychological research on illusions has been to explain illusory impressions. That was not our purpose. We sought to understand how information can be present and effective for the observer in spite of illusions. Surely, it is obvious that the explanation of an illusory appearance of different sizes of parts of a figure is distinct, logically, from the analysis of information that might be available in flip transformations of the parts of the figure. Certainly, whatever causes the Sander limbs and Jastrow shapes to appear different in size can be operating at its fullest capacity both prior to the flip and after the flip. The effects that are caused need not change. The flip adds information but does not necessarily change the illusory impression. The information resulting from the flip is not a matter for traditional psychophysics, although the impressions of size are the subject matter of psychophysics. Psychophysics is interested in quantifying amounts of change. However, knowing the quantity of a change is not the same thing as knowing the significance of a change. The significance of the nonchanges and changes are the subject matter of ecological psychology. Psychophysics is silent on the meaning of nonchange during a $180^{\circ}$ reversal.

The inference theories of perception were not explicitly addressed by our experiments. Consider what these theories would make of our results and contrast that with the ecological account. We deal explicitly with one of the illusions-the Jastrow-but what we say is equally applicable to both.

In the case of the Jastrow curves, an inference theorist would contend, the observers would notice that they do not see the two shapes as the same size. However, if the two shapes were different in size, when the apparently smaller one replaced the apparently larger one, it should have filled less space. It does not. Hence, the two must be equal. This, the theorist emphasizes, is an explanation that describes an inference.

A key problem with an inference explanation is that it is applicable sufficiently widely, ad hoc, as to be no more than the claim that perception is successful at its task. Consider the following: Pattern $X$ enters the visual activity of the perceiver. The person perceives "an elephant" correctly. The inference theorist reasons that on the basis of $\chi$, the perceiver infers that there is an elephant present. Notice the difference in emphasis between the inference account and ours. We note the information that is present. The inference theorist notes the information and then claims it can only be used by making an inference. Why does this extra step get added? We find the inference account to be empty. It argues at times that perceivers use "inadequate proximal stimuli" when given an array taken by the theory to be impoverished in some regard and concludes the observers must therefore have inferred the environmental "distal stimulus." At other times, the inference account holds that the input is not impoverished and that it then acts as a legitimate, adequate basis for a correct inference. In this manner, inference is said to be pervasive. If so, we can conclude 
that inference is deemed to be present under all circumstances; hence, the argument is bereft of useful distinctions between perceptual conditions.

It may seem strange that the inference theory is brought into action both when adequate information is provided to the observer and when the information is impoverished. However, there is a consistent theme to both circumstances, providing the motivation for the inference account. Inference theory holds that the meaning of a perceptible array is understood only following an inference. At bottom, the inference thesis is that an optic pattern is meaningful only if an inference is added to it. Hence, if a pattern is adequate it justifies an inference. If a pattern is inadequate it requires an inference.

What, then, can enable inference theory to make a distinction between adequate and inadequate patterns of light in the first place? The inference theory presupposes that there can be adequate, informative patterns of light. The ecological theory of perception is indeed aimed precisely at establishing the conditions and criteria for checking that a given pattern of light, in a particularly structured environment, is informative about its origins.

In this vein, we suggest that basic and proper work for perception theory is to isolate and describe the conditions under which informative transformations (and invariants in their transformations) are to be found. Meaning is not added by an inference, in ecological theory, but is present in the light available in an environment.

We must also point out that the inference account just presented of the Jastrow experiment hinges exactly on a definition of perception that is inadequate. "I do not see the shapes as the same size," our inference theorist has the perceiver report. Consistent with Gibson, we emphasize that "seeing" is not simply the having of impressions. Our basic point is that awareness of size equality, as a result of direct observation of the results of a transformation, need not be accompanied by size impressions that are equal. Awareness of the properties of the environment-the meaning of the observed nonchange-is part and parcel of perception.

Furthermore, we must point out an inconsistency that undermines the inference theory. If perception (in the sense of size impressions) is based on inference and people infer that the Jastrow $\mathrm{C}$-shapes are equal in size, then they should see them as equal in size (in the sense of size impressions). Alas, for the inference theory, they do not. Observers report that the C-shapes "look" unequal but "are" equal, following the observations made possible by the change of location of the two shapes.

Finally, we should add that our experiment was not concerned with information processing. We have not tried to establish what happens in the first microseconds of observation and how information is coded, stored, and recalled. The inference theory makes claims about how information is used and is often supported by processing theorists, who think that research on processing will reveal inferences being made, albeit unconsciously. We think that this aim 
is still unrealized after decades of such research and that it is based on wrongheaded analysis of the locus of meaning (not in the optic information, but in the head, following an inferential step) and doomed to failure. However, because we have not addressed the issue of information-processing stages directly, we have no evidence with which to confront the informationprocessing version of inference theory in its home territory. We must plead that we are reluctant to go looking for evidence that something does not exist. We are more willing to point out flaws in the inference theory's fundamental presuppositions.

In ecological analysis, perception is not the having of impressions that then have to be interpreted (as though by a homunculus). The dogma that observations without concepts are blind is rejected, insofar as it distinguishes observations from meaning. In the first place, the impressions the observers reported were not meaningless sensations that had to be interpreted before reference to objects was involved. Rather, they were undoubtedly of objects. In the second place, the responses to questions about what was really true were based, we argue, on relationships holding between physical parts of the displays. The responses indicated the observers' awareness, and the awareness was given by observing the world (not observing impressions). Third, "the qualities of visual experience that are specific to the receptor stimulated are not relevant to information but incidental to it" (Gibson 1979/1986, p. 263), implying a new theory of cognition. Cognition does not follow as a stage after perception; rather, perception includes within it a component of knowledge and meaning (and, indeed, memory and expectation with respect to flips). The perceptual awareness (of properties of the world) resting on properties in transformations, ecological theory argues, includes (a) awareness of the continuing existence of a surface that has just been occluded, (b) awareness that a surface that just came into view previously existed, and (c) awareness of the shape and size of an occluded surface. All of these involve awareness of occluded surfaces. Here, we propose that people can have awareness of the properties of shapes in illusions. When surfaces are occluded, people have simultaneous awareness of an object in front and another behind from their vantage point. When illusions are present, they can simultaneously have impressions of the object accompanied by awareness of the true properties of the object.

Gibson, Kennedy, and Toleno (1967) argued against the view that illusions should teach people not to trust their senses but only to trust the intellect. Gibson et al. studied the apparent bending of a straight stick partially immersed in water. They contended that rotation of the stick provides information about the true straightness of the stick, revealing the correct properties of the object in a context giving rise to illusion. They wrote that an event in time, as distinguished from a fixed thing in space, could contain the information for the correct shape. Registering or detecting this information is "not a process of reasoning or of correcting impressions" (Gibson et al., 1967, p. 124). The incorrect impressions remain while the stick rotates and once the stick is static 
again, they are the only impressions reported by the observer. However, the observer, viewing the static stick after the transformation has stopped, can report that the stick is actually straight despite the impression of being bent. The information is evident as a result of the transformation and is not evident when only the static display is given. Gibson et al. concluded that the distinctive feature present in a transformation, not any intellectual construct, may be what enables observers to register what is correct despite illusion. Our contribution here to ecological psychology is to apply this reasoning to geometrical illusions of size. That is our advance on Gibson et al. (1967), who applied the argument to illusory bending in an optical illusion, and Kennedy and Portal (1990), who applied it to symmetry properties of shape.

As a coda, we invite attention to the general issue of transformations, invariants and their meaning. Our focus is on a particular problem for realists: the argument from illusion and the veil of appearance. We have no license, then, for a general treatment of transformations and information. Others, however, are actively seeking a general treatment. Interestingly, Shaw, Flascher, and Mace (1992) did try to characterize the general goal while tackling the problem that "what appears is often different from what is" and realism must confront theories that deal in "the currency of appearance rather than reality" (p. 2). They asked, "why misleading appearances of $\mathrm{x}$ (some object or event) arise rather than $x$ simply revealing itself for what it is" (Shaw et al., 1992, p. 4). In keeping with our comments on definitions of perception, they construe "perceiving $X$ " as detecting information about $X$. As they noted, most studies on event perception lie in an epistemological vacuum: "Too often the only explanation given for how the event in question was perceived was to describe some hypothetical mechanism" (Shaw et al., 1992, p. 5). They noted that the mechanism "undergoes a given state transition whenever the event undergoes a correlated transition" ( $p$. 5). Shaw et al. also noted, tartly, that "the two may be coextensive (i.e. occur together) and yet not be cointensive (i.e. mean the same thing)" (p. 6). Shaw et al. (1992) also pointed out that if events "point beyond themselves (what philosophers call their intentionality), of what consequence is this pointing? And for whom?" (p. 6).

Akin to Shaw et al. (1992), we have asked about the meaning of nonchange. In the context of geometrical illusions, nonchange across a transformation (exchange of places) can mean two things that appear to be different sizes are the same size. Observers of these transformations can be aware of "what is" while reporting that something "appears" different from what it is. The illusion is finessed by the transformation.

\section{ACKNOWLEDGMENTS}

This article was presented at the International Conference on Event Perception and Action, Amsterdam, August 25-30, 1991. 
We thank Robert Shaw and David Givner for comments on an earlier version of this article.

\section{REFERENCES}

Ayer, A. J. (1940). Foundations of empirical knowledge. New York: Macmillan.

Berkeley, G. (1963). A treatise concerning the principles of human knowledge. Lasalle, lL: Open Court. (Original work published 1710 )

Gehringer, W. L., \& Engel, E. (1986). Effect of ecological viewing conditions on the Ames' distorted room illusion. Joumal of Experimental Psychology: Human Perception and Performance, 12, 181-185.

Gibson, J. J. (1966). The senses considered as perceptual systems. Boston: Houghton Mifflin.

Gibson, J. J. (1986). The ecological approach to visual perception. Hillsdale, NJ: Lawrence Erlbaum Associates, Inc. (Original work published 1979)

Gibson, J. J., Kennedy, J. M., \& Toleno, T. (1967). A study of the stick-in-water illusion with children. Project Literacy Reports, 8, 116-124.

Holt, E. B., Marvin, W. T., Montague, W. P., Perry, R. B., Pitkin, W. B., \& Spaulding, E. G. (1912). The new realism. New York: Macmillan.

Hume, D. (1978). A treatise of human nature (2nd ed.). Oxford, England: Oxford Universiry Press. (Original work published 1740 )

Kant, 1. (1965). Critique of pure reason (W. C. Boyce Gibson, Trans.). New York: Macmillan. (Original work published 1781)

Kennedy, J. M. (1987). Lo, perception abhors not a contradiction. In S. Petry \& G. Myers (Eds.), Perception of illusory contours (pp. 253-261). New York: Springer-Verlag.

Kennedy, J. M., \& Portal, A. (1990). Mllusions: Can change of vantage point and invariant impressions remove deception. Ecological Psychology, 2, 37-53.

Locke, J. (1959). An essay conceming human understanding (2 vols.). New York: Dover. (Original work published 1689)

Meinong, A. (1960). The theory of objects. In R. M. Chisholm (Ed.) \& I. Levi, D. B. Terrell, \& R. M. Chisholm (Trans.), Realism and the background of phenomenology (pp. 76-117). Glencoe, IL: Free Press. (Original work published 1904)

Mill, James. (1967). Analysis of the phenomena of the human mind (Vol. 1, 2nd ed.). New York: Augustus M. Kelly. (Original work published 1869)

Mill, J. S. (1979). An examination of Sir William Hamilton's philosophy. In J. M. Robson (Ed.), Collected works of John Stuart Mill (Vol. 9). Toronto: Universiry of Toronto Press. (Original work published 1865)

Natsoulas, T. (1991). "Why do things look as they do?" Some Gibsonian answers to Koffka's question. Philosophical Psychology, 4, 183-202.

Nunn, T. P. (1909). Are secondary qualities independent of perception? Proceedings of the Aristotelian Society, 10, 191-218.

Parks, T. E., \& Hui, L. (1989). Pictorial depth and the Poggendorf illusion. Perception and Psychophysics, 46, 465-468.

Runeson, S. (1988). The distorted room illusion, equivalent configurations and the specificity of static optic arrays. Joumal of Experimental Psychology: Human Perception and Performance, 14, 295-304.

Schiff, W. (1988). Unpacking the Ames room: What the transactionalist's brain doesn'r tell the ecological psychologist's ear. Intemational Society for Ecological Psychology Newsletter, 3(4), 6-9.

Shaw, R. E., Flascher, O. M., \& Mace, W. M. (1992). Dimensions of event perception. Unpublished manuscript. 